\title{
CAPTURE AND DOCUMENTATION: KAGA PARK
}

\author{
C. Morganti ${ }^{1}$, C. Bartolomei ${ }^{1}$ \\ ${ }^{1}$ Department of Architecture, Alma Mater Studiorum - University of Bologna \\ (caterina.morganti4, cristiana.bartolomei)@unibo.it
}

\section{Commission II}

KEY WORDS: H-BIM, Laser scanner, Scan-to-BIM, Tokyo, Japan

\begin{abstract}
:
The article deals with the topic of Historic Building Information Modeling (H-BIM) applied to the historical architecture of an urban park within the Itabashi district of Tokyo. The document will address a methodological discussion concerning the construction of parametric models of historic buildings in the park starting from laser scanner. The research is prompted by the modern need to have databases full of exhaustive information, through which we can preserve the historical heritage present in the Japanese reality, monitoring the conditions and planning the future. This work is carried out in collaboration with the Nihon University of Tokyo, the Alma Mater Studiorum University of Bologna, the Itabashi municipality and the Topcon industry. The work is preparatory for the development of the redevelopment project of the park, through the reuse of its buildings, the arrangement of the green and urban furniture pursuing the objectives of maintaining the historical memory of the place and its harmonization in the urban context, creating a further pole of attraction for citizens and visitors.
\end{abstract}

\section{INTRODUCTION}

This research's main target is the examination of tools and methods for the application of H-BIM, while understanding his critical issues and proposing useful solutions for what is concerning this still undefined and unstructured field.

The project's purpose, however, is not just the mere 3D modeling production, semantically structured and parametrics going from a bunch of points and obtained by a high definition digital survey: the intention is to define H-BIM criteria and application methods during the whole process, from the project to the execution of the opera and maintenance (Figure 1).

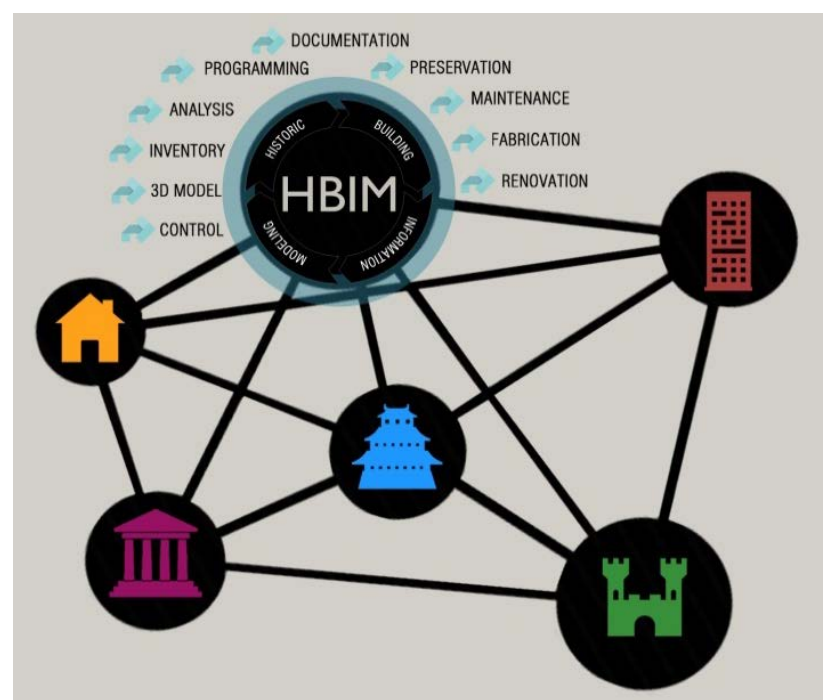

Figure 1: Structuring of H-BIM.

In this context one of the most critical elements connoting the application of H-BIM founded informatic protocols in the field of historical building is strictly related to his constitutive heterogeneous features.

The research is indeed willing to investigate, through an experimental development process, the range of possible applications of this analysis methodology, contemplating the usage of laser scanner techniques and tridimensional modeling combined with H-BIM (Acierno et al., 2017; Bianchini et al., 2016). In this perspective building tracking techniques are given great significance as an essential and decisive passage to guarantee the proper correspondence between geometricaldimensional and constructive contents during the subsequent project and executive steps.

A proper certification of the initial condition, that is to say the evaluation and faithful restitution of the original state, constitutes a primary vehicle to give reliability to the whole process and results, in harmony with four macro activities: diagnostics, project, construction, management.

A great number of pilot researches about BIM implementations on historical buildings shows that the passage from 2D traditional representations to a restoration project based on 3D parametric model can't deal only with tools and personalized procedures: it is necessary to really understand the use of parametric tools to renovate both the whole conservation process and valorization of historical heritage (Letellier and Eppich, 2015). It's better to approach the theme through an analysis of tools way before starting the development of tools themselves: this is the aim of this research.

The article deals with the topic of H-BIM applied to the historical architecture of an urban park within the Itabashi district of Tokyo.

The document will address a methodological discussion concerning the construction of parametric models of historic buildings in the park starting from laser scanner detection.

The research is prompted by the modern need to have databases full of exhaustive information, through which we can preserve the historical heritage present in the Japanese reality, monitoring the conditions and planning the future. The integration between the BIM systems and the three-dimensional acquisition systems seems to naturally pass from an informatic process of interfacing and "translating" the different data obtained (Arayici et al., 2017).

This is one of the problems to be faced in the near future: the road on which to invest significant resources, both economic and intellectual. The European and Japanese markets are ready and need these tools to be structured in an integrated way in a totally transparent if not invisible workflow. 
3D scanners (lasers, optical, etc.) have been a professionally used technology in the survey and topography sector for about ten years, especially in the areas of analysis of existing (asbuilt), shipbuilding, infrastructures and clearly in the field of restoration and conservation. Similar reflections and parallelisms can be carried out by analyzing the evolution of the $\mathrm{CAD}$ systems, from their conception to their advancement in BIM three-dimensional numerical systems, especially suited to the executive design phase of the construction sector.

It is evident that greater complexity in managing / acquiring information has led to ever greater specializations.

The evolution of computing power and software development has led to improvements in the use of systems and their ability.

To date, the geometries that structure the BIM systems and the clouds of point (generated by the three-dimensional acquisition systems) are structurally different. BIM is based on the description of the geometry on the basis of a number of defined or definable parameters (this in the most complex systems, often migrated from mechanical CAD systems), while the clouds of points are millions of geometric coordinates, "points" in space. The cloud of points produced by the laser scanner allows staying in the three-dimensional environment from the survey phases up to the design phases.

The BIM environment allows keeping all the collected data, organizing them in a solid, complete and integrated information system. Building Information Modeling is destined to become an integral part of the construction industry (Pritchard et al., 2017).

Scan-to-BIM capable of converting point clouds and laser survey data into complex 3D models BIM is the first fundamental step of the BIM process for any architect, engineer, construction manager or contractor involved in redevelopment, renovation and renovation projects.

In fact, today Japan, much more than in the past, has an interest in the restoration and enhancement of the historical and architectural heritage. In the present case, this is a current topic of Tokyo, such as the renewal of the urban park now called Kaga Park (Figure 2), located in the Itabashi district.

For the enhancement and modernization of this park, the first committee was created in the year 2008 which aims to complete the redevelopment in the year 2025 following the inspiring principles that are to ensure the identity of the places, enhance the green areas and existing buildings in the optic of the inclusion of these spaces within the city and as an extension of the tourist offer of the country.

The Itabashi park, which will probably change its name in Itabashi Historical Park, covers an area of about 260m x 130m crossed by the Shakujii river.

The area was chosen for the construction of gunpowder and ballistic tests, so there are still industrial archaeology buildings related to this type of activity and in particular there are a ballistic tube launch site, a laboratory of combustion, a deposit of gunpowder, explosives laboratory and test rooms.

The site was chosen in a strategic position as it is relatively close to the city center but at a safe distance for possible explosions and near the watercourse for moving the mills and for drawing water.

Starting from a historical-critical research already carried out by the work, the aim was to recreate the entire urban environment and its buildings through the acquisition of point clouds with laser scanners and then return three-dimensionally all the parts of the complex (Cera and Campi, 2017).

In particular, the generation of the BIM model of two buildings (Figure 3, Figure 4) has been developed within the complex. The main objective of the redevelopment of the park and of the architectural and cultural history contained in it offers the opportunity to develop a case study applying the modern laser scanner and to return the survey using H-BIM (Shishido et al., 2018).

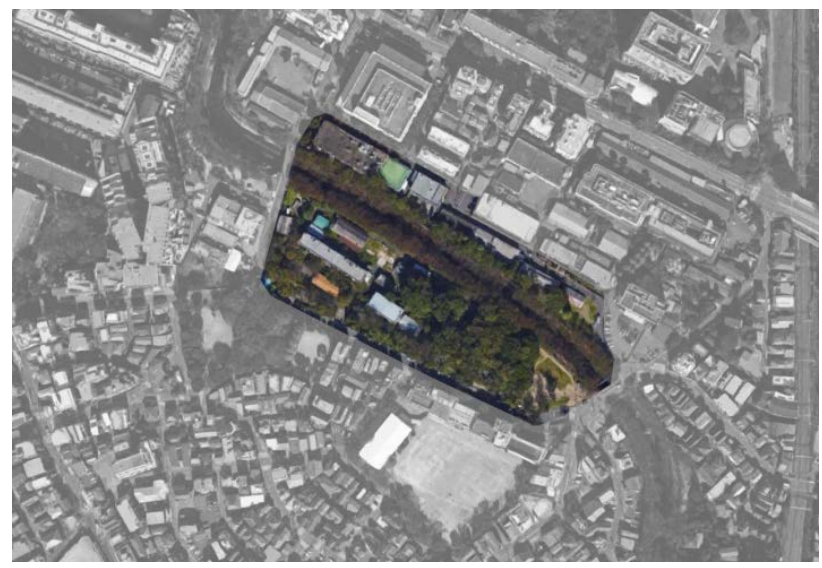

Figure 2: Plan of the Kaga park area.

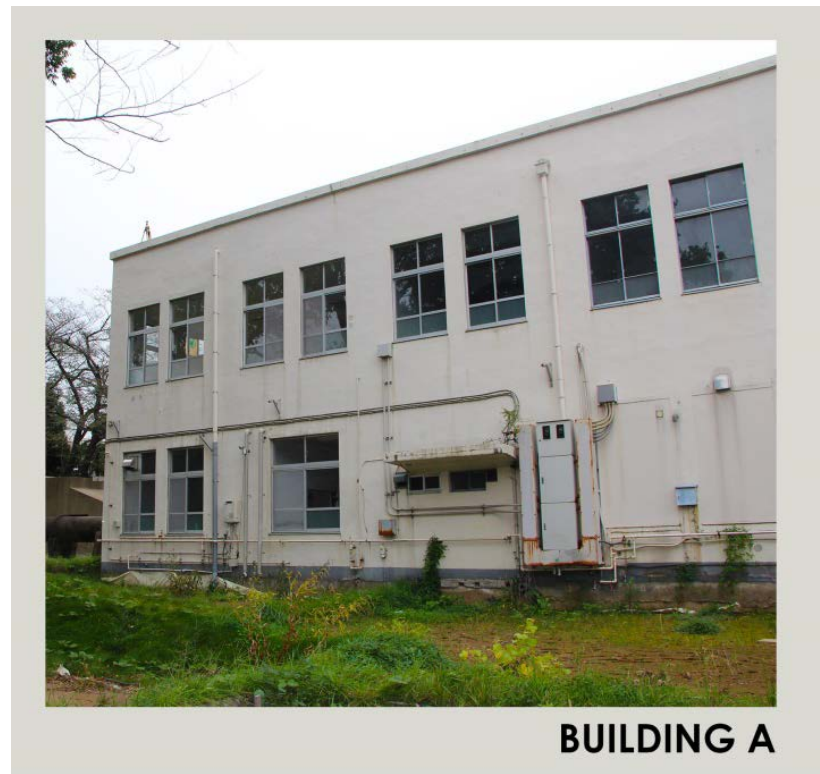

Figure 3: Building case of study (A).

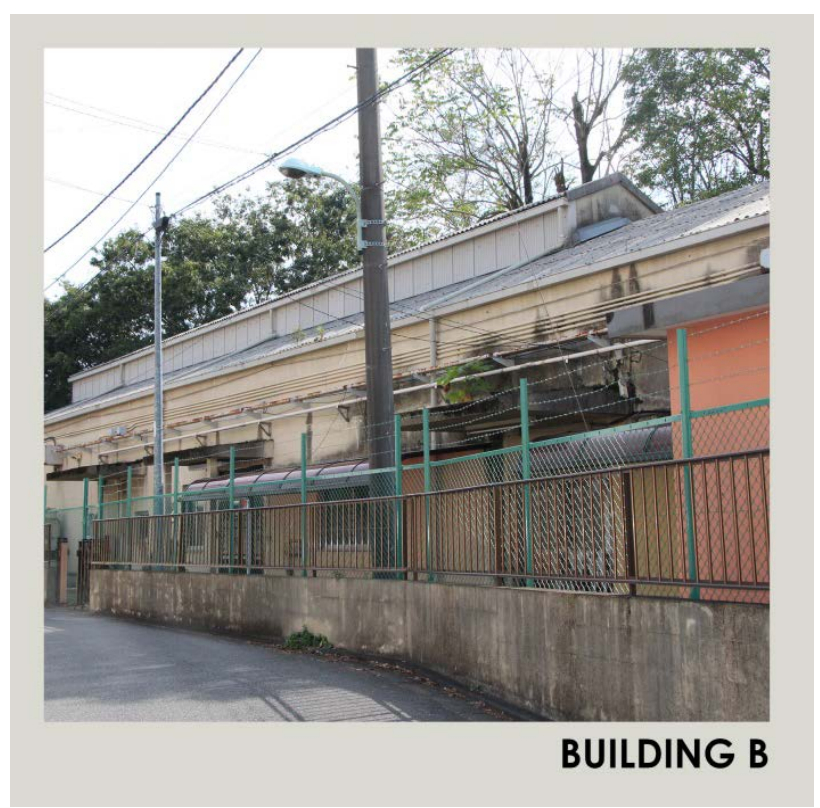

Figure 4: Building case of study (B). 


\subsection{History of Kaga Park}

Itabashi-ku, Tokyo, belongs to the 23 Tokyo neighborhoods and is located northwest of the city.

It borders to the east with Kita Ward, Toshima Ward to the south, Nerima Ward to the west, Wako City in the prefecture of Saitama with the river Shirako to the northwest, and Toda City to the north with the river Arakawa to the north.

It has an area of $3217 \mathrm{~km}^{2}$ and a population of about 550,000 people. The terrain consists of floodplains along the Arakawa River in the northwest and the Muroto Tadashi district, a volcanic plateau in the central and southwestern part. A small river flows in this plateau.

It is the Shakujii river with the Kodaira water source flowing in the southern part of the district from east to west, the basin has a relatively wide and delicate valley.

In this valley was built in the year 1876 the laboratory and production center of gunpowder of Itabashi where stood the largest villa daimyō of Edo, in the same year the palace was built for the production of artillery cannons of the Army.

It is believed that the Ministry of Hyōbu has issued a judgment that the damage to the Itabashi Town district can be minimized in the event of an explosion by installing a pyrotechnic manufacturing facility in this relatively large place.

At the adjacent Noguchi Research Institute (Kaga 1 - chome 8), there is a part of the equipment to verify the performance of the ammunition called a trajectory tube.

From the aerial photographs of 1964 it can be seen that the pipe extended directly on Mt. Hirao, in the Kaga park, to the center of the mountain. In 1896, the completed explosives factory began to operate as the main artillery factory of the Itabashi factory.

Subsequently, this factory was renamed "Platekiti gunpowder manufacturing place" and the final name is Tokyo Army / Itabashi factory.

Subsequently, other industries arose in the area and not only for the production of weapons or gunpowder but also for example of paper mills.

This establishment of state-owned factories and large companies mainly in Itabashi, the Takino River and the Oji area became the basis of industrial development in Japan. It can be said that the area is only one of the starting points for modernization in Japan (Figure 5).

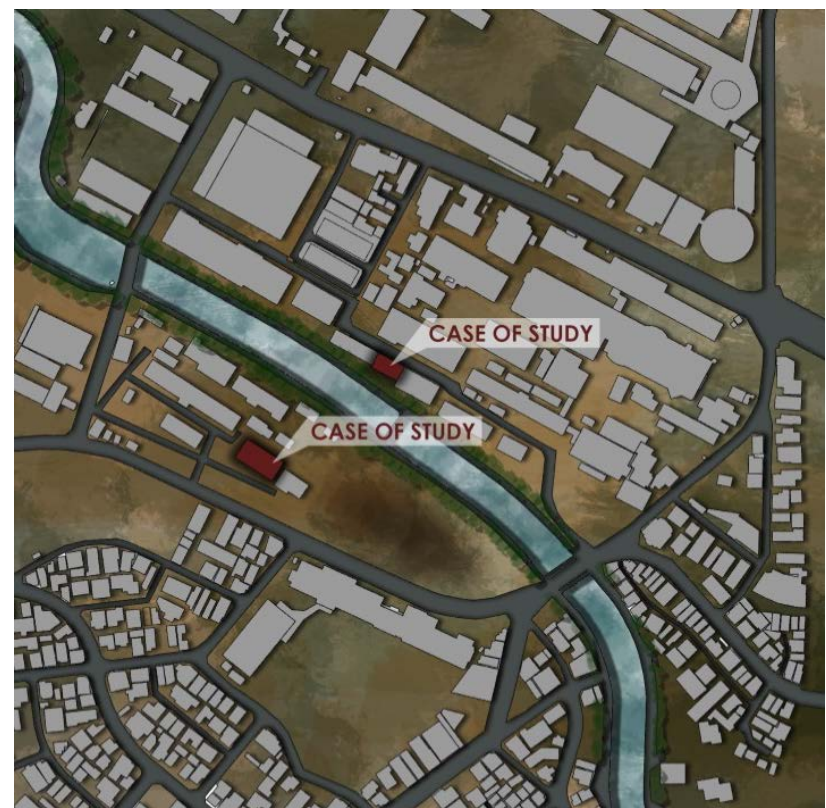

Figure 5: Kaga park area and cases of study.

\section{RELATED WORKS}

The international scientific community has been dealing with Heritage for several years BIM (H-BIM), proposing methods, approaches and computer programs cut out on the needs of the existing building stock.

The H-BIM research horizon is moving towards the generation of objects with different descriptive levels, relying on detection methods accurate as laser scanners or high definition digital photogrammetry, but also through the construction of reusable standard libraries (Dore and Murphy, 2017).

According to the H-BIM approach, the parametric objects representing the architectural elements can be built geometrically starting from manuals and treatises (Zheliazkova et al., 2015).

This modeling procedure is based on the use of libraries of architectural components typical of historic buildings and algorithms that automatically combine the elements of the library and generate parts of the building. Subsequently, altering certain parameters, the operator is able to refine the model by making it fit with survey data.

The integration of H-BIM models into GIS systems represents the new approach to the documentation of the existing building patrimony (Berlo and Laat, 2010). This is possible thanks to the implementation and management of large amounts of data, as survey from laser scan campaigns and photogrammetry (Azhar, 2011). H-BIM is therefore placed in a field of research of great interest and this is also shown by the various projects in progress. This is demonstrated in the context of the EU H2020 research framework program under two projects: DURAARK (Durable Architectural knowledge) and INCEPTION (Inclusive cultural heritage in Europe through 3D semantic modeling). The first project, INCEPTION, includes a special focus on H-BIM graphic, semantic, and topological interoperability, in which the graphic and semantic information of interest in cultural heritage, its sources and suppliers, the technologies and formats, and the applicable directives have all been defined and agreed as an object of research. There are several commercial and academic researches have studied the automated reconstruction of existing buildings from point clouds, in particular in recent years increased interest in the study of parametric models that allow a complete management of the model (Bianchini et al., 2018). According to the currently shared scientific literature, research on H-BIM uses different approaches: some only use commercial BIM platforms to develop "as-is-model" BIM models and, subsequently, the parametric to create H-BIM libraries.

Others combine BIM commercial platforms with modeling tools for virtual building development and H-BIM libraries.

Finally, some combine commercial BIM platforms, Open Source software (OSS) and non-BIM auxiliary tools with GIS software for modeling and archiving 3D models.

\section{DEVELOPED METHODOLOGY}

The work process has seen the development of different phases: total station acquisition and laser scanner acquisition, point cloud processing, generation of a first Revit model created based on .dwg drawings, point cloud import in Revit for the correction of the hypothesized model, creation of Revit family to be included in the final model.

Regarding the existing drawing documents Board of Education, Municipality of Itabashi surveyed

3D BIM model data are based by their documents. Regarding existing 3D data of GIS, the grounds data in 3D BIM model are made with DEM (digital elevation model) by Geo spatial information authority, Ministry of Land, Infrastructure and Transport. 


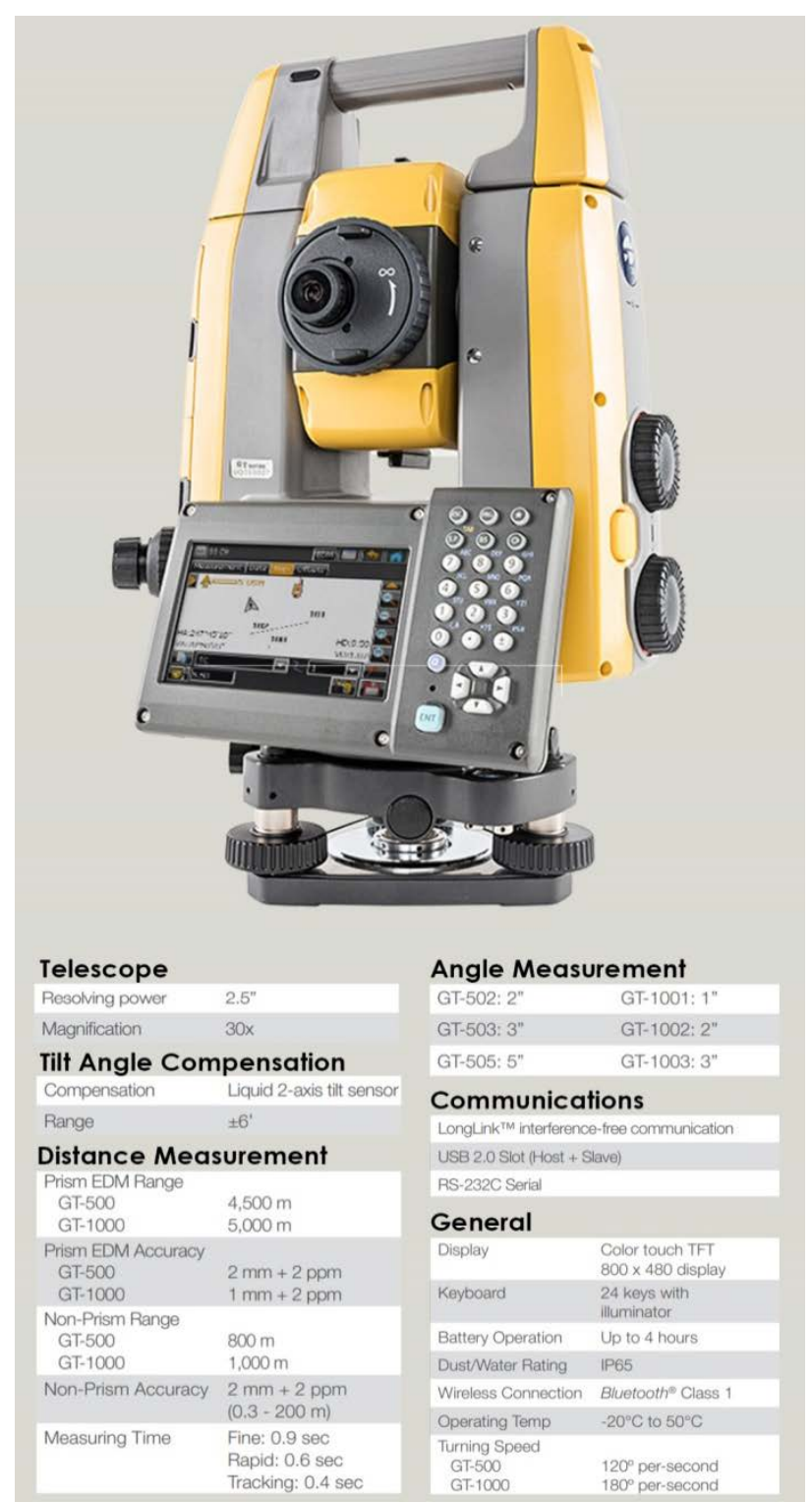

Figure 6: TopCon Total Station GT Series.

Buildings outline data and road edge data are very important information for combination of BIM data and GIS data in terms of positioning. For organization of laser scanning, provisional 3D BIM model with GIS data is very important and useful to make work (survey and make point crowd data) efficiency (Wang et al., 2015). The first operation, after historical research, was to identify the necessary tools and methods. To do this, a meeting was held with Topcon technicians, identifying the most suitable tools for the purpose, called Topcon Total Station GT Series (Figure 6) and Topcon GLS-2000 series Laser Scanner (Figure 7). Based on the potential of this tool, the survey campaign to be carried out in the field has been planned (Mukupa et al., 2017). In the following figures the survey project of the case study B (Figure 8, Figure 9). The red dots correspond to the positioning of the total station tool while the yellow dots to the positioning of the laser scanner tool.

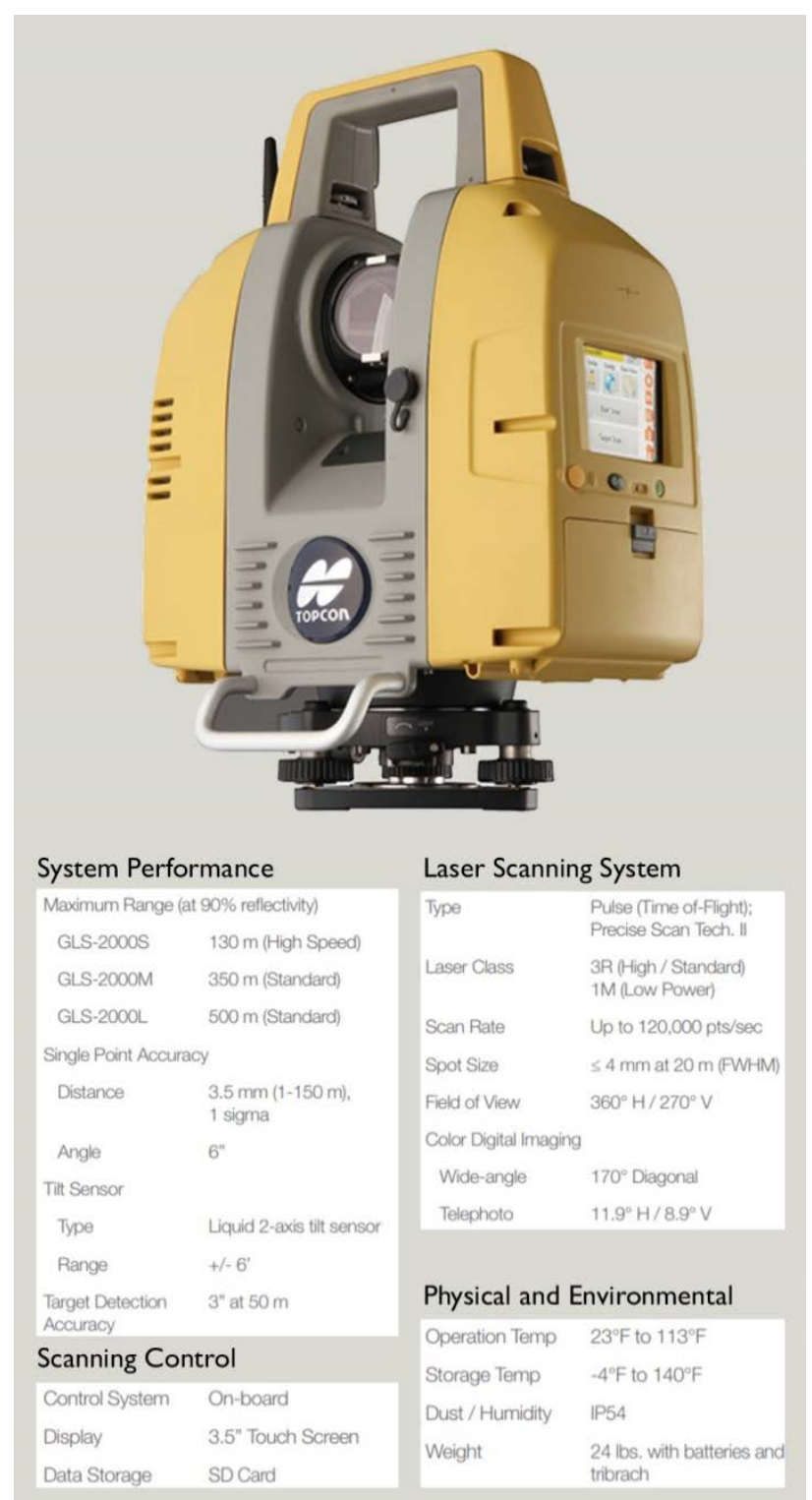

Figure 7: Topcon GLS-2000 series Laser Scanner.

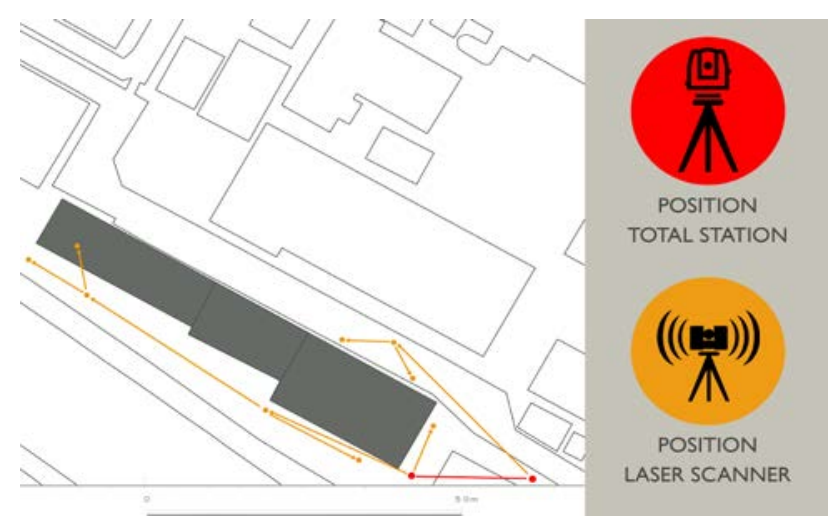

Figure 8: External survey project (building B). 


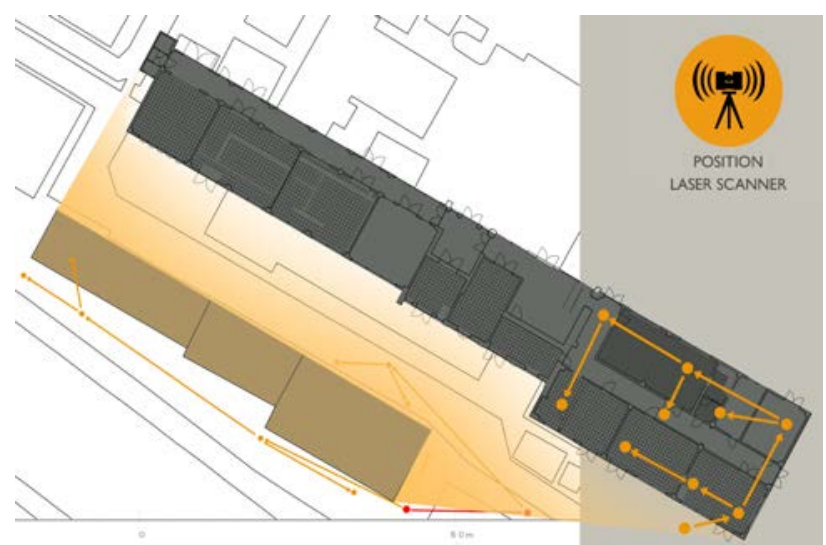

Figure 9: External survey project (building B).

The first operation is to build the Revit model from the existing drawings (Figure 10, Figure 11).

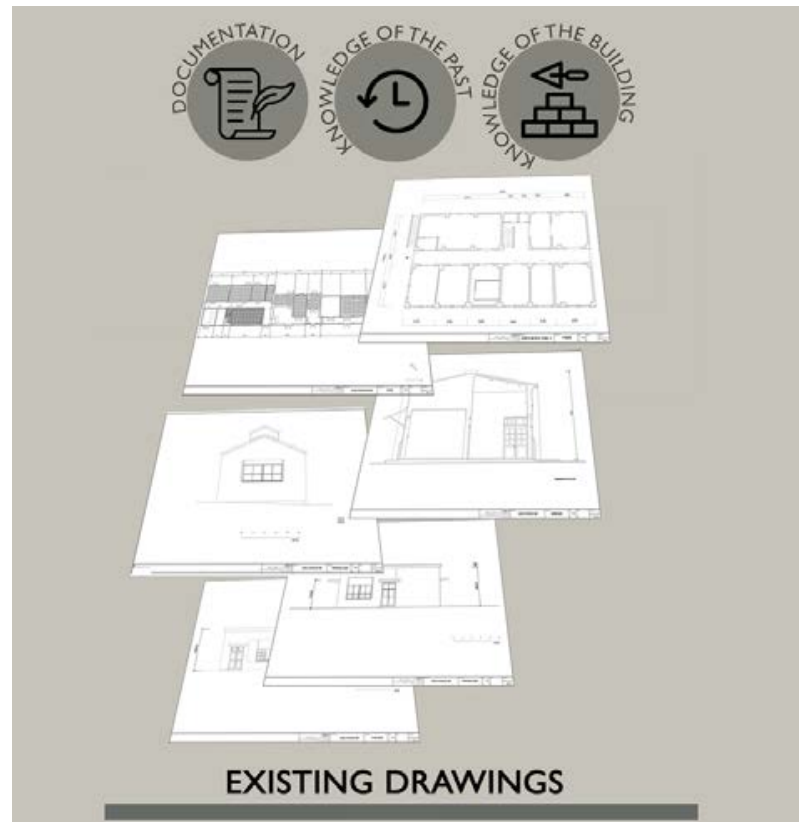

Figure 10: From exiting drawings to hypothesized Revit model.

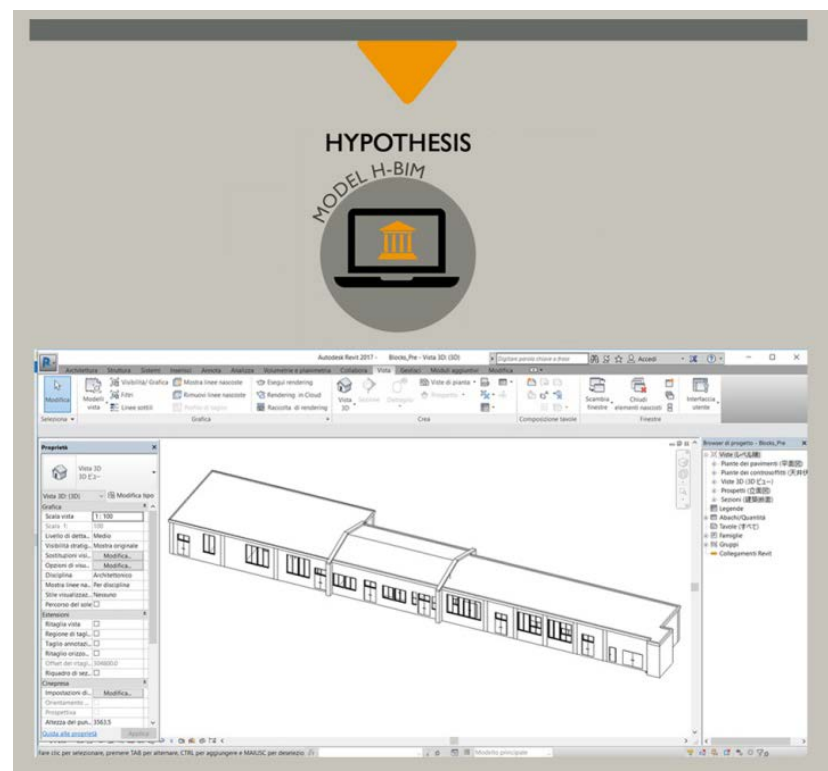

Figure 11: From exiting drawings to hypothesized Revit model.
The second operation is build the cloud of points and manage it in Recap (Figure 12).

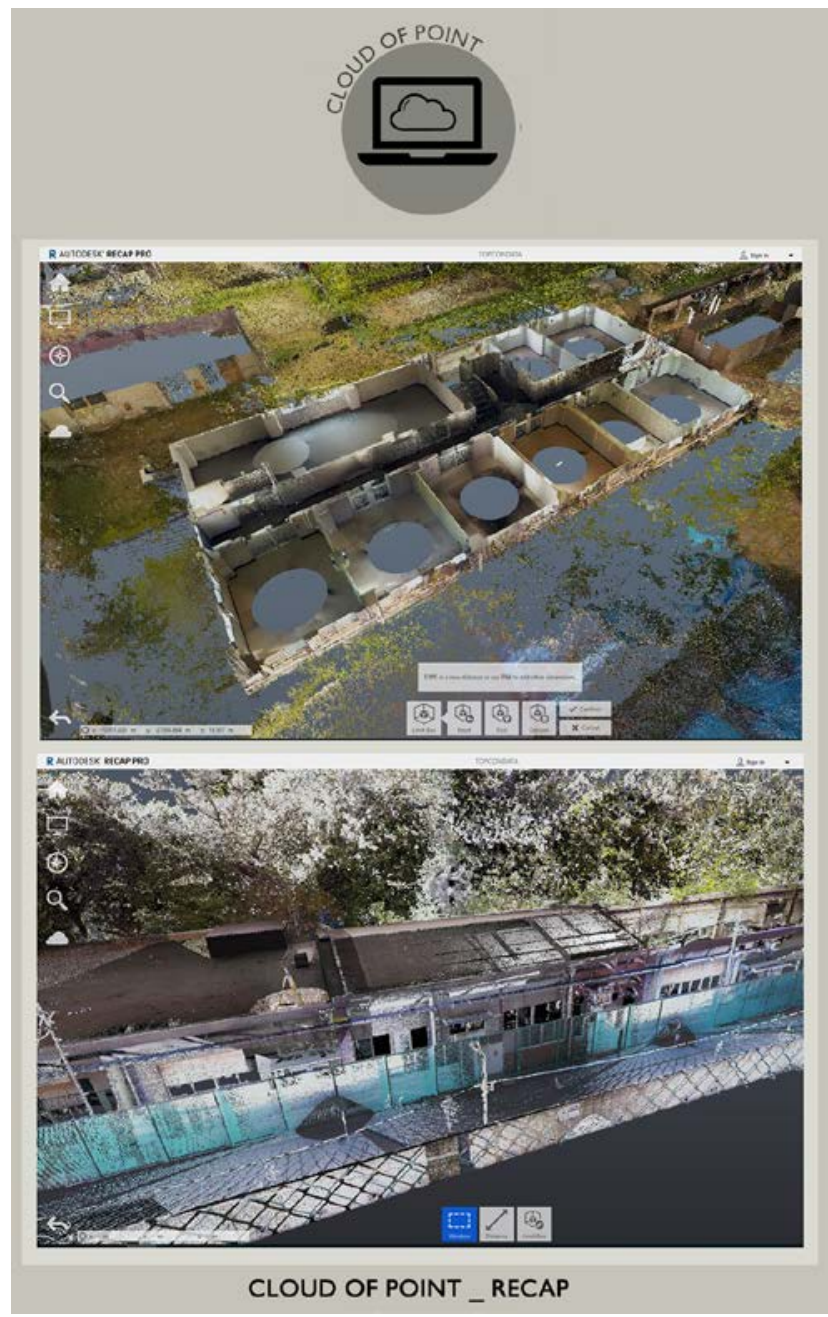

Figure 12: Cloud of point.

The third one is merge them into one model, overlapping the hypothesized model and the cloud of point perfectly (Figure 13) (Baik, 2017).

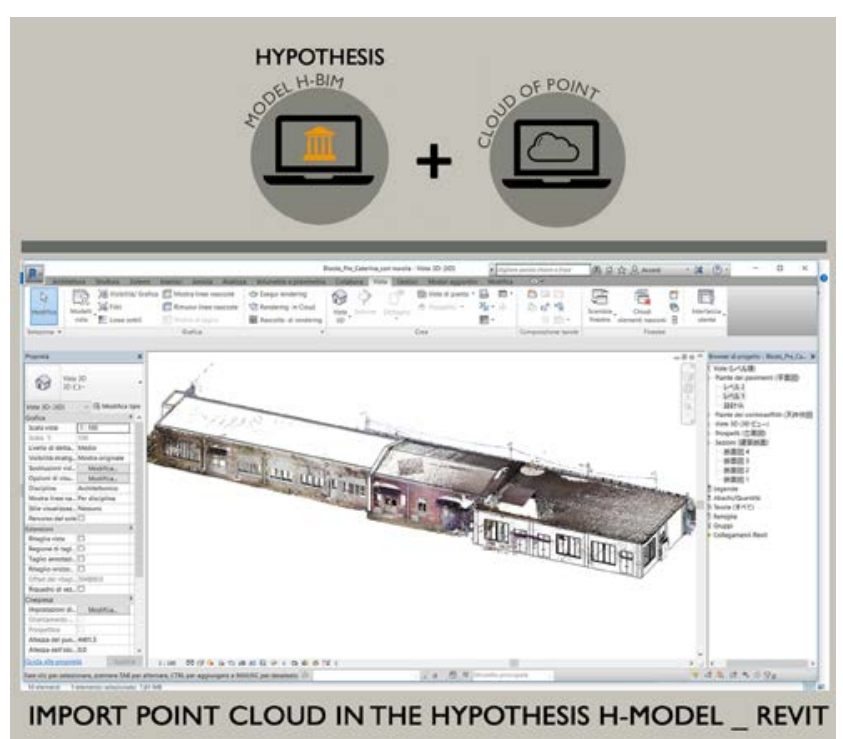

Figure 13: Overlapping hypothesized model and cloud of point. 
Subsequently, the corrections are made to the model assumed on the basis of the cloud of point (Figure 14).

\section{a

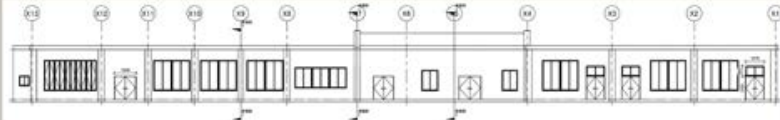 \\ ADJUSTMENT MODEL REVIT ACCORDING TO THE CLOUD OF POINT}

Figure 14: Model assumed on the basis of the cloud of point.

At this point, the Revit Family had to be created to generate the correct final Revit model (Wang et al., 2015).

To do this, the following steps were followed (Figure 15):

1. isolate the element for which you want to create the family in Recap (Figure 16);

2. export file in extention .pts;

3. import file in Rhinoceros (Figure 17);

4. export file in extention .dwg;

5. import file in Revit (Figure 18);

6. create a family in Revit (Figure 19).
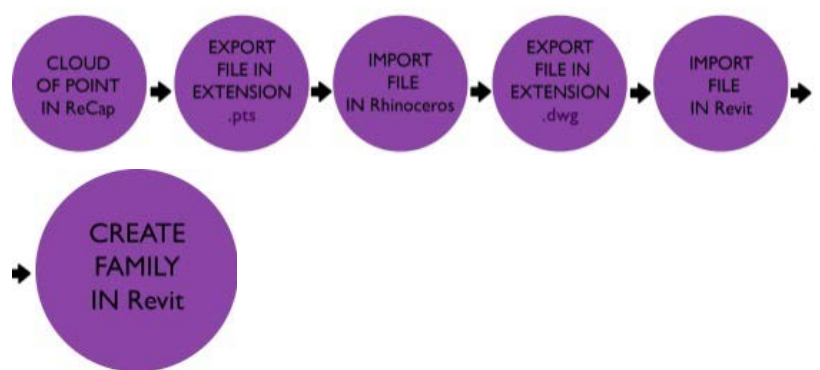

Figure 15: Steps to create Revit Family.

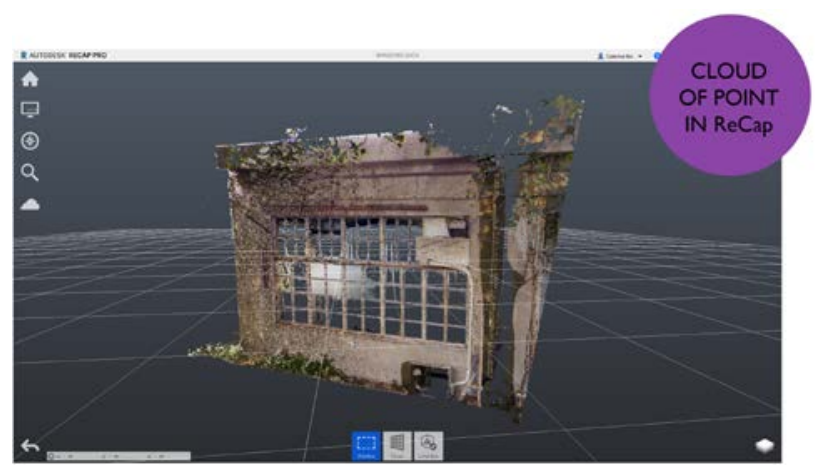

Figure 16: Isolate element in Recap.

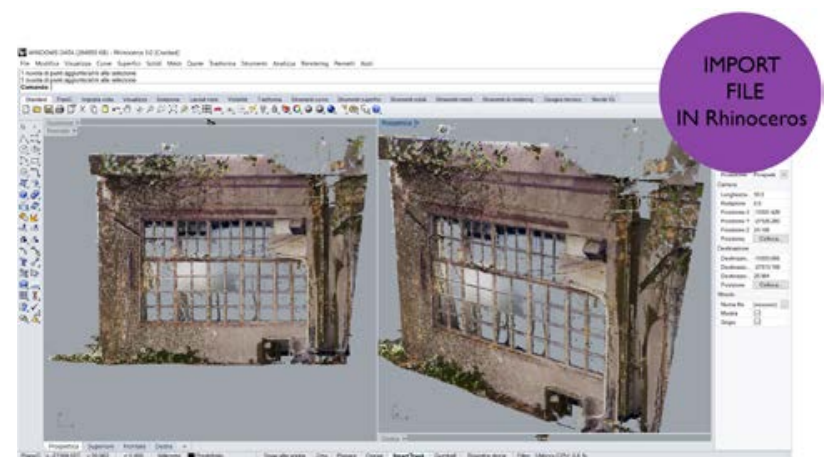

Figure 17: Element in Rhinoceros.

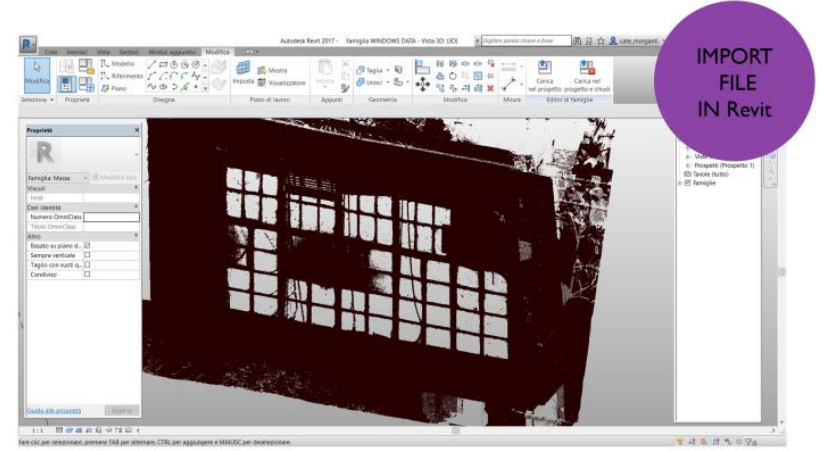

Figure 18: Element extention.dwg import in Revit.

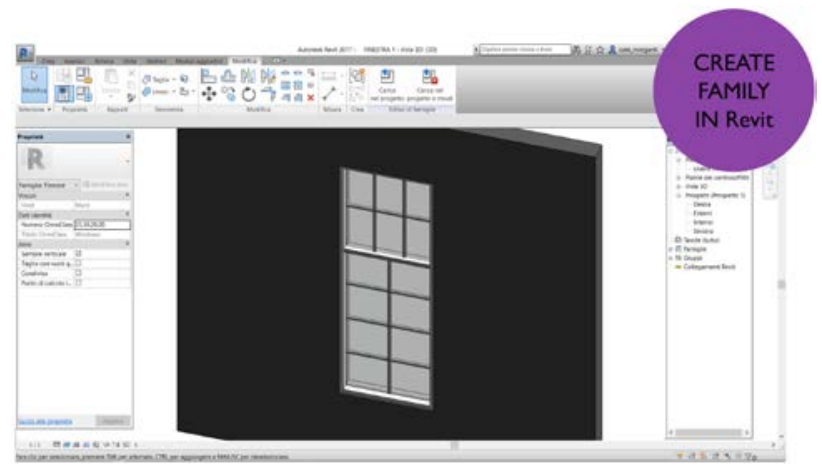

Figure19: Creation Family in Revit.

All Revit Family created were imported into the previously adjusted model, thus obtaining the final model (Figure 20, Figure 21).

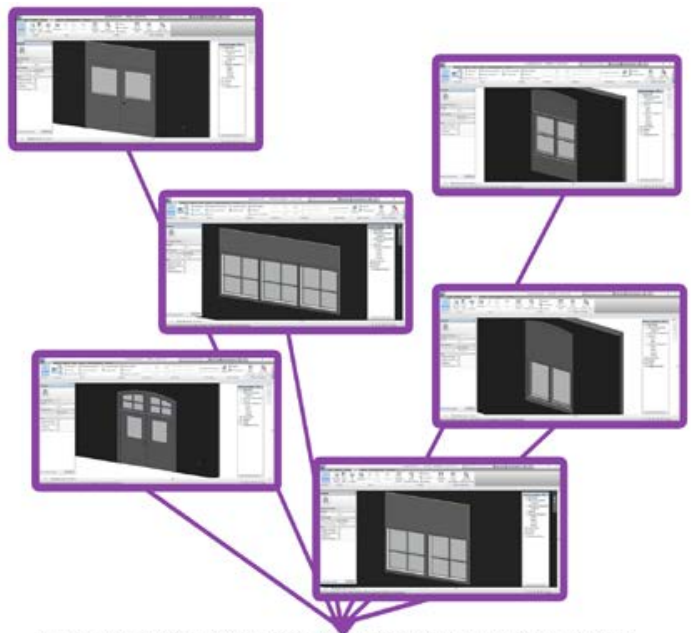

ALL REVIT FAMILIES ARE LOADED TO CREATE THE FINAL MODEL

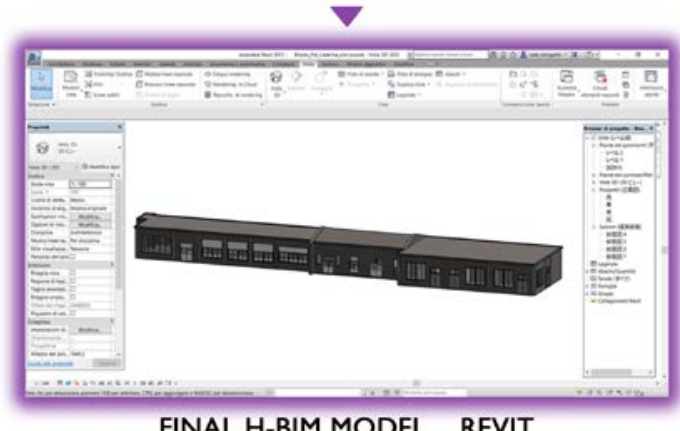

FINAL H-BIM MODEL_ REVIT

Figure 20: Revit Family created imported into the model. 


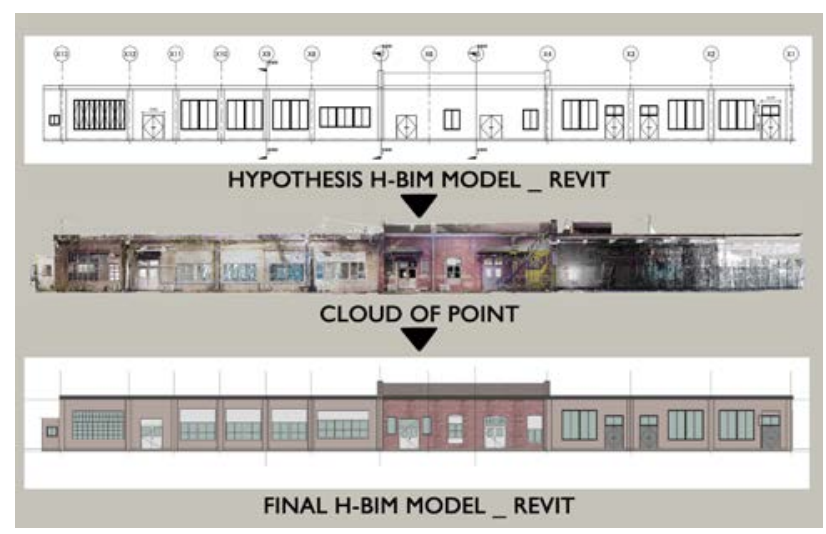

Figure 21: From hypothesized model to final model.

\section{CONCLUSIONS}

The survey, the data processing and the restitution of the model of the first building examined gave the possibility to understand the potentialities and the critical aspects of the method.

This first survey can therefore be defined as a test for planning and optimization of the same for the study of subsequent buildings and related open spaces.

In addition to testing the potential of the laser scanner instrument, we tried to optimize its use by identifying the minimum number of stations necessary to achieve the desired precision. In addition, all the time necessary to carry out the various operational phases, such as: data processing to obtain the point cloud, and then the 3D geometric model, and subsequently the BIM model, were evaluated (Johansson et al., 2015).

In this way it is possible to estimate the number of people, the tools to be used, the times for carrying out all operations up to the completion of the entire complex in order to identify times, costs and results.

During development the use of the H-BIM approach could be experimented combining clouds of points and photogrammetric tables resulting from the survey campaigns carried out for the construction of a library of parametric families and a series of models of buildings (AA.VV., 2013)

Models that, subsequently, will be inserted into a GIS system, exploiting data interchange formats according to the standards for the construction of an information platform.

Each technical element will then be decomposed into the layers that make it form, identifying, for each of them, the characteristics of the materials constituents.

The database will be designed so that we can incorporate this type of information according to an overall logic: most of the buildings that are find in Kaga Pask present technological solutions analogous, the database will try to rationalize this condition, too in the light of a possible repeatability of the interventions.

Within the database it will be expected to insert an abacus of technical elements and related technological solutions, both at the level of the de facto state and at level of hypothesis of intervention on each technical element.

The platform information, thanks to the collected data, will be able to perform analyses timely improvement on each technical item filed.

However, the automatic Scan-to-BIM process has some limitations (Hong et al., 2015).

Reading and interpreting the quality data of an architecture is very difficult for computers. And there are no software tools capable of automatically modeling point clouds in parametric objects. Moreover, the calculation algorithms are effective only for the segmentation and automatic modeling of point clouds representing flat surfaces or primitive geometries, instead they generate inaccurate results when trying to represent complex and irregular geometries of historical architectures.

The modeled architectural components will be part of the $\mathrm{H}$ BIM parametric libraries.

The increased use of H-BIM libraries would facilitate the interdisciplinary exchange of semantic and geospatial objects / data between experts of different disciplines in the field of architectural heritage (Hosseini et al., 2018).

The approach provided by this research that will combine BIM tools with GIS tools and auxiliary software could be an effective solution for graphic management and modelling (point clouds) and semantic data (historical-constructive information).

\section{REFERENCES}

AA.VV., 2013. AIA Document G202, Project Building Information Model Protocol Form, AIA.org,

Acierno, M., Cursi, S., Simeone and D., Fiorani, D., 2017. Architectural heritage knowledge modelling: An ontologybased framework for conservation process. J. Cult. Heritage, Vol. 24, pp.124-133.

Aicardi, I., Chiabrando, F., Lingua, A.M. and Noardo, F., 2018. Recent trends in cultural heritage 3D survey: The photogrammetric computer vision approach. J. Cult. Heritage.

Arayici, Y., Counsell, J., Mahdjoubi, L., Nagy, G.A., Dweidar, K. and Hawas, S., 2017. Heritage Building Information Modelling; Taylor \& Francis: Abingdon.

Azhar S., 2011. Building Information Modeling (BIM): Trends, Benefits, Risks, and Challenges for the AEC Industry. In: Leadership and Management in Engineering, Vol. 11(3).

Baik, A., 2017. From point cloud to jeddah heritage BIM nasif historical house-case study. Digit. Appl. Archaeol. Cult. Heritage, Vol. 4, pp.1-18.

Berlo, Lv. and Laat, Rd., 2010. Integration of BIM and GIS: The Development of the CityGML GeobBIM Extension.

Bianchini, C., Inglese, C. and Ippolito, A, 2016. The role of BIM (Building Information Modeling) for representation and managing of built and historic artifacts. In: Disegnare con, Vol.9, pp.10-11.

Bianchini, C., Inglese, C., Ippolito, A., Maiorino, D. and Senatore, L.J., 2017. Building Information Modeling (BIM): Great Misunderstanding or Potential Opportunities for the Design Disciplines? In: Handbook of Research on Emerging Technologies for Digital Preservation and Information Modeling; IGI Global, pp. 67-90.

Bruno, S., De Fino, M. and Fatiguso, F., 2018. Historic Building Information Modelling: Performance assessment for diagnosis-aided information modelling and management. Vol. 86, pp. 256-276.

Cera, V. and Campi, M., 2017. Evaluating the Potential of Imaging Rover for Automatic Point Cloud Generation. In: Int. Arch. Photogramm. Remote Sens. Spat. Inf. Sci. Vol. XLII-2/W, pp.147-154. 
Dore, C. and Murphy, M., 2017. Current State of the Art Historic Building Information Modelling. In: Int. Arch. Photogramm. Remote Sens. Spat. Inf. Sci. Vol. 42, pp. 185-192.

Hong, S., Jung, J., Kim, S., Cho, H., Lee, J. and Heo, J., 2015. Semi-automated approach to indoor mapping for 3D as-built building information modeling. In: Comput. Environ. Urban Syst. Vol. 51, pp.34-46.

Hosseini, M.R., Roelvink, R., Papadonikolaki, E., Edwards, D.J. and Parn, E., 2018. Integrating BIM into facility management: Typology matrix of information handover requirements. In: Int. J. Build. Pathol. Adapt.

Johansson, M., Roupé, M., Bosch-Sijtsema, P., 2015. Real-time visualization of building information models (BIM). Autom. Constr. Vol. 54, pp. 69-82.

Letellier, R. and Eppich, R., 2015. Recording, Documentation and Information Management for the Conservation of Heritage Places.

McArthur, J.J., 2015. A building information management (BIM) framework and supporting case study for existing building operations, maintenance and sustainability. Procedia Eng, Vol.118, pp.1104-1111.

Mukupa, W., Roberts, G.W., Hancock, C.M. and Al-Manasir, K., 2017. A review of the use of terrestrial laser scanning application for change detection and deformation monitoring of structures. Vol. 49, pp.99-116.

Pritchard, D., Sperner, J., Hoepner, S. and Tenschert, R., 2017. Terrestrial laser scanning for heritage conservation: The Cologne Cathedral documentation project. ISPRS Ann. Photogramm. In: Remote Sens. Spat. Inf. Sci. Vol. 4, pp 213220.

Shishido, H., Ito, Y., Kawamura, Y., Matsui, T., Morishima, A., Kitahara, I, 2017. Proactive preservation of world heritage by crowdsourcing and 3D reconstruction technology. In: Proceedings of the 2017 IEEE International Conference on Big Data, p. 4426.

Wang, C., Cho, Y.K. and Kim, C., 2015. Automatic BIM component extraction from point clouds of existing buildings for sustainability applications. Vol. 56, pp.1-13.

Zheliazkova, M., Naboni, R. and Paoletti, I, 2015. A parametric-assisted method for 3D generation of as-built BIM models for the built heritage. WIT Trans. Built Environ. Vol.153, pp. 693-704. 